\title{
E-health: A Health Promotion Tool for Brazilian Amazon Region
}

\author{
Roosevelt Silva Bastos, Aline Megumi Arakawa, Angela Xavier, José Roberto Magalhães Bastos \\ Magali Lourdes Caldana
}

\begin{abstract}
Objective: This study aimed to describe the e-health activities of Project USP in Rondônia to promote health into the Amazonian Brazilian State Rondônia in different types of educational resources.
\end{abstract}

Methods: Population of Monte Negro county was reached by the e-health promotion activities including tele-education for community health workers, teachers and local health professionals with the videoconferencing, CD-ROM development and $\mathrm{C}$ ybertutor technologies. The population reached was calculated by the reach of these professionals into their daily activities.

Results: The e-health activities held by ProjectUSP in R ondônia are reaching local stakeholders to expand the spread of health knowledge within a region with severe difficulties of access to information and health care. These stakeholders, mainly working locally in the educational and auxiliary health professions, are seizing their opportunity to provoke autonomy in the population they work with, disseminating information among children in public schools and health care, possibly reaching more than 1,380 families.

Conclusion: $\mathrm{E}$-health activities showed to be important tool for health promotion to Amazonian communities. People living in regions with difficult access to many social needs, such as riverside communities, must be respected as citizens and thus their right to health must be ensured, which is provided in the Brazilian constitution, and it should be promoted through education, prevention and adequate health services.

Keywords: E-health, Tele-education, Community.

How to cite this article: Bastos RS, Arakawa AM, Xavier A, Bastos J RM, Caldana ML. E-health: A Health Promotion Tool for Brazilian Amazon Region. World J Dent 2012;3(4):320-323.

\section{Source of support Nil}

Conflict of interest: None declared

\section{INTRODUCTION}

E-health is an important challenge for B razil in reaching distant nonprivileged localities and their populations. The World Health Organization (WHO) who has been attempting to diminish the disparities between and within countries and B razil is no exception. The gap between social classes has been shrinking in recent years but important disparities may be observed between the South and Southeast and the North and N ortheast regions, regarding education, the job market and health matters. A dditionally, the health professional distribution throughout the country is not equal, as the concentration is still in the Southeastern states. The B razilian epidemiological data clearly reflects the social disparities present in the country and e-health activities may be an effective option to contribute to the reduction of these differences in health promotion.

The Constitution of $1988^{1}$ is one of Brazilian society's greatest achievements in public health policy. Article 196 discusses health as a right of citizenship and requires the social determinants confrontation to promote it. The Brazilian primary health care reorganization started with SUS in an attempt to overcome challenges resulting from the epidemiological transition, social inequalities and difficulties in financing and management of SUS and to ensure quality health services to the whole population, especially nonprivileged regions, such as the A mazonian region of the state of R ondônia. ${ }^{2}$

This way, e-health might be a viable tool throughout the B razilian national territory and its extensive resources misallocation, so facilitating access to distance education, research development by educational centers as well as population assistance, mainly in remote rural regions where there are several difficulties in access to health care, ${ }^{3}$ in this sense, tele-education, a branch of telemedicine, seek to employ the use of interactive technologies to help improve the health promotion.

The proposal of this study is to present the Project USP in Rondônia's educational experience through e-health technologic tools for health promotion based on a health education training course for nonhealth professionals in the A mazonian region, specifically the Brazilian state of Rondônia.

\section{METHODS}

\section{Procedures}

A presentation will be realized explaining the activities developed by a project whose name is 'USP in Rondônia', covering e-health procedures, in a city of Brazil A mazon region.

\section{Project USP in Rondônia}

In 2002, the Faculty of Dentistry at Bauru (FOB/USP), started extension activities with undergraduate, graduate, postgraduate students, staff and professors in the city of 
M onte N egro, in Dentistry, Speech L anguage Pathology and Hearing sciences. A ctivities conducted personally are health education, disease prevention and health care activities aimed to promote health and improve quality of life. Expeditions run twice a year in January and July, being preceded by a preparatory course, over 2 weeks with undergraduate and postgraduate participants to study the population's reality about actions developed during each expedition. ${ }^{4}$

The municipality of $\mathrm{M}$ onte $\mathrm{N}$ egro has a total population of 14,091 inhabitants, according to the Brazilian Institute of $\mathrm{G}$ eography and Statistics, 2010 , of which $53 \%$ of subjects are male and $45 \%$ are female. Approximately half the population lives in rural areas. ${ }^{5}$

\section{Participants}

The project looks for involving people who will be able to make health promotion and health education. So the focus here will be in the training courses for public schoolteachers, for community heal th workers ( $\mathrm{CHW}$ ) and assistant health professionals. All of them were invited to participate in these training courses, without any cost.

\section{E-health Activities}

A mong the distance educational activities realized were videoconferencing, a cybertutor and the development of an educational material. These courses were developed in order to provide local stakeholders with the knowledge necessary to reflect critically about their living and health conditions, seeking ways to improve their choices and autonomy.

\section{RESULTS}

\section{Health Training Description}

Health training courses were directed to assistant health and education professionals with focus on the areas of Dentistry, Speech L anguage Pathology and Hearing sciences. The courses were conducted in person and by distance, with the videoconferencing technology.

Health assistant professionals, especially $\mathrm{CHW}$, were trained with information related to the aging process and the most common physiological changes related to speechlanguage and hearing sciences. The study conducted in person was realized during the expeditions of the 'USP in Rondônia' in Monte Negro. Discussions aroused when $\mathrm{CHW}$ brought to light what was happening in the communities where they work everyday, enabling reflection on what has been exposed to them and even individual assimilation, which characterizes the practice of health education. The course was given in 20 hours in person, and the approached content were inserted in a support material (CD-ROM) which was given for the CHW, to make the consulting on it if it be necessary. ${ }^{6}$

The health education for the public school teachers was conducted in two parts, the face-to-face encounters along the expeditions. The issues dealt with were aspects related to children and adolescents' speech-language and hearing pathology and dental health. In times when the course was taught, graduate students also were present and assisted at times when discussions were encouraged. At all times, professors and postgraduate students were also present.

Later, these schoolteachers from public primary and secondary level of education and assistant health professionals from public service were offered a distance training course provided by tele-education through videoconference - interactive technologies in real timeenabling knowledge construction as a means to facilitate access to remote areas, with precarious health conditions and far from large urban centers. The focus of the activity offered was health education, with modules for teachers. The course lasted 90 hours, 55 hours by distance and 35 hours in person. However, at times, this educational process was hindered due to the barriers that emerged, among them, the signal quality required for the videoconference proper completion which was sometimes interrupted due to bad weather- heavy A mazonian rains and winds in M onte Negro or even when a mango dropped through the electric wire, as happened once. Moreover, the damage triggered by the rains also seriously interfered in the participants' presence in videoconferences for those who lived in rural areas, as they could not get around to the urban area in time.

Furthermore, a cybertutor was developed to the participants with focus about the aging process divided into modules developed covering topics, such as quality of life and speech therapy and dental changes in the elderly as well as primary health hygiene needs. A $n$ online platform for integration of content on the subject was used. These functioned as support material for lessons and reinforcement of the previous videoconference. The material was used by 20 teachers from public primary and secondary education of $\mathrm{M}$ onte N egro. The teacher contact with the children and their families enabled the spread of appropriate knowledge and habits to promote health.

The Figure 1 shows the activities realized and reached population with direct and indirect way. The topics hereafter will present these data:

- Community health workers: A total of $44 \mathrm{CHW}$ were invited to participate in the activities but only 29 attended the meetings. The health training reached $29 \mathrm{CHW}$, and $20.7 \%$ of these attend urban dwellers and $79.3 \%$ rural 


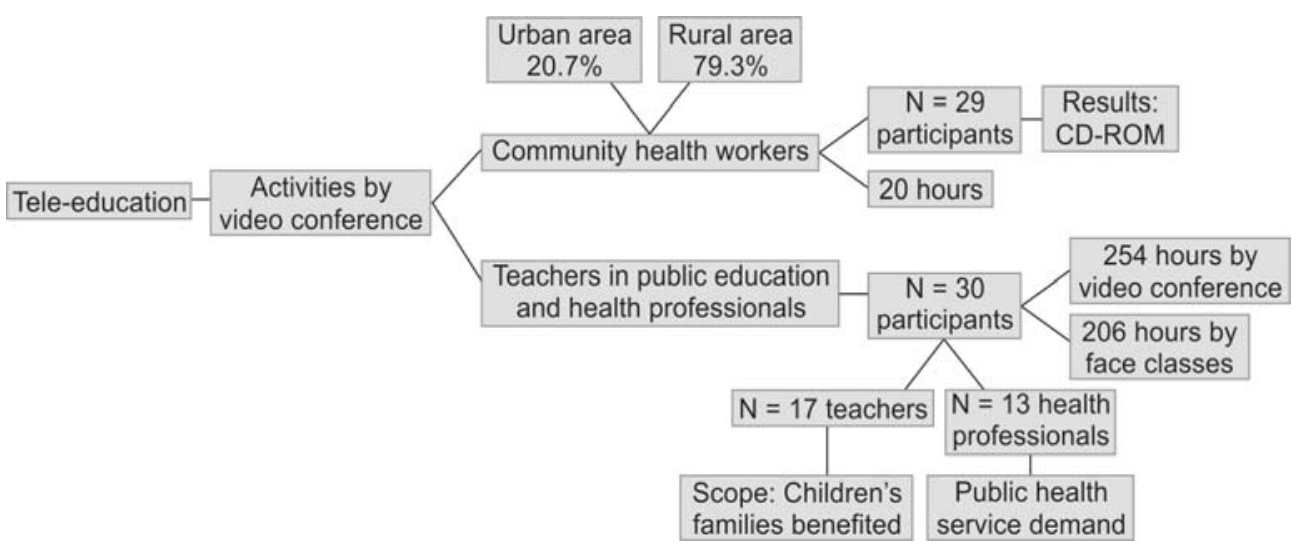

Fig. 1: E-health activities realized in the Amazon region

dwellers. Rural area is a large territory there and without the CHW insertion people would have huge difficulties in accessing public services especially health services, being essential the $\mathrm{CHW} \mathrm{s}$ ' work to facilitate the access to health care services and consequently the improvement of this population's quality of life.

- Teachers of public education: 17 teachers attended whole training course with direct benefit for each teacher family. Furthermore, about 30 children compose each classroom, thus indirectly benefiting their families.

- Health professionals: This group was composed by nurses, nursing technicians and psychologists, which their w ork is directly focused with, the entire population each day by demand, hence, spreading health information and promoting health daily.

The courses offered to health professionals and teachers provided a better understanding about the issues of oral health, general and speech as well as the importance of continuing health education activities with the people, for it has the ability to consciously make choices and these choices are best for your health and quality of life.

The e-health activities offered to health assistant professionals provide an opportunity for local professional development, promoting an effective role in the community, mainly living in the countryside, with severe difficulties of access to information and health care. Thus, these education and health professionals will be able to work with the community in order to enable the population to exercise the autonomy to reflect and make choices with the chance for the healthiest. These successful experiences may be expanded and multiplied to other communities in the A mazonian interior where access to information and training courses is restricted nevertheless e-health tools might reach by the internet.

\section{DISCUSSION}

The municipality of M onte $\mathrm{N}$ egro is located within the State of $R$ ondônia, a region far from $B$ razilian central areas, where the professionals who live there have difficulties acquiring new knowledge and conducting refresher courses, continuing education or specialization, due to difficulties in moving to the big centers or lack of courses provided to local professionals. Thus, distance education is an essential tool that enables the qualification of these professionals, which would otherwise be very difficult.

The improvement of internet connectivity for heal th care may be promoted by telecommunication technologies, such as the telehealth, thus diminishing professional isolation. Telehealth is perceived as having a positive impact on several dimensions of health service delivery, reflecting in the workforce in remote regions. ${ }^{7}$

Health promotion presupposes the recognition of health as a right of citizenship, expressed in better living conditions, more resolute services and comprehensive actions, with a focus on encouraging intersectoral and community organization for the exercise of social control. Therefore, health promotion is achieved through the articulation between different public sectors and private ones. ${ }^{8}$

The training courses offered to health professionals and educators living in the municipality of $\mathrm{M}$ onte N egro aim to qualify these professionals to act as multipliers of information and health education to provide the urban and rural populations ability to critically evaluate their life situation and health and to seek ways to improve them, also to enable the known of their rights as citizens and charge of the public offer quality services to the population. The courses were realized with participation of 59 individuals directly, but it is important to see the people indirectly benefitted in the community.

The concept of empowerment is related to the process by which communities, organizations and/or individuals become able to develop the power to act effectively on the necessary changes in their lives. The individual level refers to the empowerment built by the individual to have the freedom to reflect on the goals that he or she wants to pursue. 
E-health: A Health Promotion Tool for Brazilian Amazon Region

Individual empowerment is a prerequisite for community empowerment and social change. In an evaluation process of the empowerment process, the evaluation of community empowerment can be based on the calculation of individual empowerment. ${ }^{9}$ In this sense, professional training aims to train professionals capable of stimulating the local population to act effectively on their living conditions and health and be aware of their rights and how to reach it.

$\mathrm{M}$ onte $\mathrm{N}$ egro has a high percentage of population living in rural areas (60\%), and this population cannot easily shift to the city, which happens sporadically, so the education of the $\mathrm{CHW}$ is paramount to conducting an active study of the health needs of this population as well as to conduct health promotion activities targeted to their needs. The work of education professionals is extremely important because they work in the formation of children, who are the future of the community, to exert influence on all of their adult life, including health education as well. Children also act as multipliers of information and learning spreading their learning in school to their family and friends.

\section{CONCLUSION}

The social determinants of health involve individual aspects and environmental aspects related to the insertion of people into society, requiring a more comprehensive approach to address the health of a population. The model of health care focused on diagnostic and clinical treatment neglects such factors. In this sense, health promotion activities provide an important contribution to the improvement of health conditions and quality of life.

Thus, e-health may be a powerful tool that enables knowledge to reach people living in areas where access to information and health attention becomes a difficult task, as Project USP in Rondônia is doing in the A mazonian region, approaching people who live in remote regions, enabling them to share experiences and thereby promoting the autonomous capacity of people who will possibly make the best choices for their health and quality of life.

\section{REFERENCES}

1. Göttems LB, Evangelista M oS, Pires M R, Silva A F, Silva PA. A history of primary health care policy in the federal district, Brazil (1960-2007): A $n$ analysis based on the theoretical framew ork of historical neoinstitutionalism. Cad Saude Publica 2009;25(6):1409-19.
2. Lima C, M onteiro A, Ribeiro E, Portugal S, Silva L, J oão-J unior $M$. Videoconferences. Systematization and experiments in telemedicine. Radiol Bras 2007;40(5):341-44.

3. W en C. Telemedicina e Telessaúde: Um panorama no Brasil. Informática Pública 2008;10(2):7-15.

4. Bastos RS, Silva RP, M aia-J unior A F, Carvalho FS, M erlini S, Caldana $M L$, et al. Dental caries profile in Monte Negro, A mazonian state of Rondônia, B razil, in 2008. J A ppl Oral Sci 2010;18(5):437-41.

5. IBGE. Sinopse do Censo demográfico. 2010 Rio de Janeiro: IBGE 2011.

6. A rakawa A. Continuing education for community health workers of Rondônia state: A Speech-L anguage and Hearing approach about the elderly health. B auru: University of São Paulo; 2011.

7. Gagnon M P, Fortin JP, L andry R. Tel eheal th to support practice in remote regions: A survey among medical residents. Telemed JE-H ealth 2005;11(4):442-50.

8. Buss P. Health promotion and public health: Contribution for a discuss between Public Health Schools in Latin A mérica. Rio de Janeiro: Fiocruz; 1998.

9. A lpay LL, Henkemans OB , Otten W, Rövekamp TA J M , D umay $A C M$. E-health applications and services for patient empow erment: Directions for best practices in the N etherlands. Telemed JE-Health 2010;16(7):787-91.

\section{ABOUT THE AUTHORS}

\section{Roosevelt Silva Bastos (Corresponding Author)}

Professor Doutor, Department of Pediatric Dentistry, Orthodontics and Community Health, Faculty of Dentistry at Bauru, U niversity of São Paulo, São Paulo, B razil, e-mail: rtbastos@fob.usp.br

\section{Aline Megumi Arakawa}

Graduate Student, Department of Pediatric Dentistry, Orthodontics and Community Health, Faculty of Dentistry at Bauru, U niversity of São Paulo, São Paulo, Brazil

\section{Angela Xavier}

Graduate Student, Department of Pediatric Dentistry, Orthodontics and Community $\mathrm{Health}$, Faculty of Dentistry at Bauru, U niversity of São Paulo, São Paulo, Brazil

\section{José Roberto Magalhães Bastos}

Professor, Department of Pediatric Dentistry, Orthodontics and Community Health, Faculty of D entistry at B auru, U niversity of São Paulo, São Paulo, Brazil

\section{Magali Lourdes Caldana}

A ssociate Professor, Department of Speech, L anguage and Hearing Sciences, F aculty of Dentistry at B auru, U niversity of São Paulo, São Paulo, Brazil 